\title{
SPIDERS OF THE NEW GENUS ARCTACHAEA
}

\author{
(ARANEAE, THERIDIIDAE) \\ By HeRBERT W. LEVI \\ Museum of Comparative Zoology \\ Harvard University
}

The new spider genus Arctachaea is erected for two rare species from western North America, closely allied to Theridion. Arctachaea differs from the latter in abdomen shape and in structure of the genitalia. The rarity of the two species accounts for the belatedness of their description.

Dr. W. J. Gertsch of the American Museum of Natural History and Dr. R. V. Chamberlin of the University of Utah have made specimens available to me. I extend my sincere thanks for their cooperation.

Arctachaea, new genus

Arctachaea (fem.) has Arctachaea pelyx as type species.

Medium sized theridiid spiders. Carapace longer than wide, thoracic depression indistinct. Eyes subequal in size, anterior eye row procurved as seen from front, posterior row straight as viewed from above. Chelicerae lacking teeth. Sternum convex. First leg longest, fourth or second leg in males second in length, third shortest. Tarsal comb with few setae. Abdomen slightly longer than high with a distinct dorsal posterior hump. Colulus absent.

Epigynum a raised area. Palpus with median apophysis

\section{Explanation of Plate 8}

Figs. 1-2 Arctachaea nordica (Chamberlin and Ivie) Fig. 1. Ventral view of chelicerae and palpus. Fig. 2. Anterior view of left chelicera. Figs. 3-6. A. pelyx new species. Fig. 3. Left palpus, expanded (C, conductor; E, embolus; M, median apophysis; R, radix; Y, cymbium). Fig. 4. Female genitalia, dorsal view. Fig. 5. Epigynum. Fig. 6. Female. Figs. 7-11. A. nordica (Chamberlin and Ivie). 7. Female genitalia, dorsal view. 8. Epigynum. 9, 10. Female. 11. Left palpus. Figs. 12-13. A. pelyx new species. 12. Palpus (Utah). 13. Palpus (Oregon). 

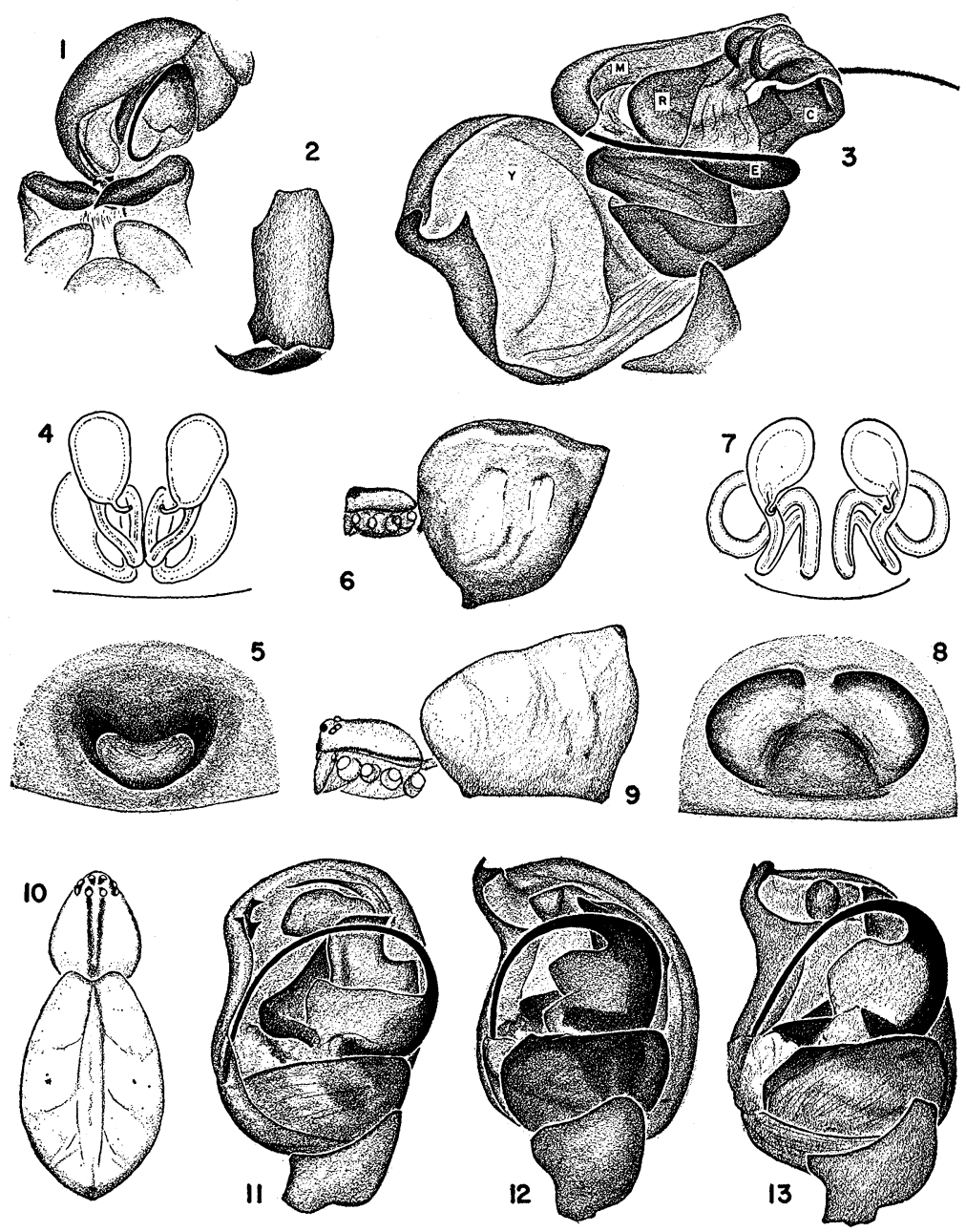

Levi - Arctachaea 
(M in Fig. 3), radix (R), conductor (C) and a long embolus (E). The cymbium (Y) is modified at its tip.

Arctachaea differs from Theridion by having a hump on the abdomen (Figs. 6, 9, 10), and in the shape and direction of the embolus. It differs from both Theridion and the closely allied Chrysso in having the tip of the male cymbium modified (Fig. 3). Arctachaea can be separated from Achaearanea which has a similar shaped abdomen in that the former has a radix in the male palpus while the latter genus does not.

Arctachaea pelyx new species

Plate 8, Figures 3-6, 12, 13; Map 1

Types. Male holotype from East Canyon, Salt Lake County, Utah, June 12, 1943 (W. Ivie) in the American Museum of Natural History.

Description. Carapace yellow-white with a median dusky band, narrowest posterior, enclosing eye region and continuing as a line across the clypeus; sides of carapace with a dusky line. Sternum with a black border on each side. Legs with some black spots. Abdomen (Fig. 6) yellowwhite with a dusky median dorsal band bordered by white. Anterior median eyes separated by one and one-quarter diameters, one-quarter from laterals. Posterior eyes separated by one diameter. Abdomen with a tubercle (Fig. 6) that of male longer than high. Epigynum with a light swollen area illustrated by Figure 5, palpus by Figures 12, 13. Total length of female $3.2 \mathrm{~mm}$. Carapace $1.02 \mathrm{~mm}$. long, $0.92 \mathrm{~mm}$. wide. First femur, $1.71 \mathrm{~mm}$.; patella and tibia, $1.85 \mathrm{~mm}$., metatarsus, $1.58 \mathrm{~mm}$; tarsus, $0.68 \mathrm{~mm}$. Second patella and tibia, $1.11 \mathrm{~mm}$; third $0.78 \mathrm{~mm}$.; fourth $1.24 \mathrm{~mm}$. Total length of male $2.7 \mathrm{~mm}$. Carapace $1.15 \mathrm{~mm}$. long, 1-10 mm., wide. First femur $2.71 \mathrm{~mm}$.; patella and tibia $3.05 \mathrm{~mm}$.; metatarsus $2.72 \mathrm{~mm}$.; tarsus, $0.91 \mathrm{~mm}$. Second patella and tibia, $1.63 \mathrm{~mm}$. ; third, $1.05 \mathrm{~mm}$.; fourth, $1.70 \mathrm{~mm}$.

Records. Utah: Salt Lake Co.: East Canyon, June 14, 1942, \& paratypes; June 21, 1942 o paratypes; June 12, 1943, \& allotype, \& ô paratypes (W. Ivie). Summit Co.: $3 \mathrm{mi}$. W. of Wanship, June 20, 1941, 우 ㅇ (W. Ivie). Oregon. 
Harney Co.: above Fish Lake, Steens Mtn., 18 mi. E. of Frenchglen, 7000-8000 ft., July 14-16, 1953, ô (V. Roth).

Arctachaea nordica (Chamberlin and Ivie)

Plate 8, Figures 1-2, 7-11; Map 1

Achaea nordica Chamberlin and Ivie, 1947, Bull. Univ.

Utah, biol. ser., vol. 37, p. 25. (Juvenile male holotype from College, Alaska, in the American Museum of Natural History).

Description. Carapace white, with a double median line and a dusky border. Sternum with a narrow dusky border. Legs white. Eyes on small black spots, anterior medians

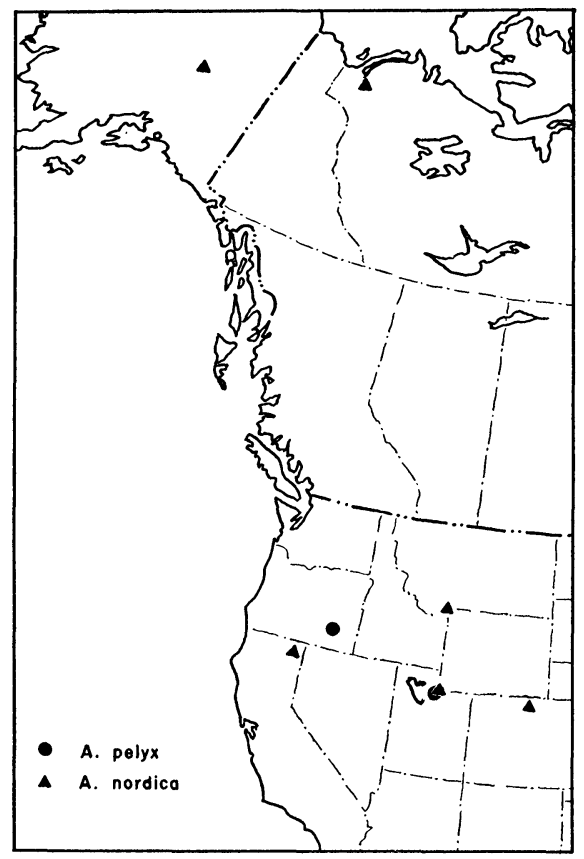

Map 1. Distribution of Arctachaea nordica (Chamberlin and Ivie) and A. pelyx new species.

one and one-third diameter apart, one-half from laterals. Posterior medians separated by less than their diameter, by one from laterals. Abdomen white with a black spot 
on posterior tip (Figs. 9, 10). Epigynum with two anterior swollen areas, and a posterior median depression (Fig. 8). Palpus of male very large (Fig. 11), cymbium $0.65 \mathrm{~mm}$. long, teeth of cymbium fitting against enlarged fang (bearing phlanges on each side) as illustrated by Figure 1. Total length of female from Montana $3.0 \mathrm{~mm}$. Carapace, 1.12 $\mathrm{mm}$. long, $0.97 \mathrm{~mm}$. wide. First femur, $2.20 \mathrm{~mm}$.; patella and tibia, $2.32 \mathrm{~mm}$.; metarsus, $1.95 \mathrm{~mm}$.; tarsus, $0.71 \mathrm{~mm}$. Second patella and tibia, $1.35 \mathrm{~mm}$.; third, $0.91 \mathrm{~mm}$.; fourth $1.56 \mathrm{~mm}$. Total length of male from Colorado $2.7 \mathrm{~mm}$. Carapace, $1.24 \mathrm{~mm}$. long, $0.98 \mathrm{~mm}$. wide. First femur, 2.60 mm.; patella and tibia, $2.74 \mathrm{~mm}$.; metatarsus, $2.40 \mathrm{~mm}$.; tarsus, $0.85 \mathrm{~mm}$. Second patella and tibia, $1.72 \mathrm{~mm}$.; third, $0.92 \mathrm{~mm}$.; fourth, $1.62 \mathrm{~mm}$.

Records. Northwest Territories: Reindeer Depot, $68^{\circ} 42^{\prime}$ : $134^{\circ} 06^{\prime}$, July 1-6, 1948, $q$; Aug. 1948, juv. $q$, juv. ô having enlarged fangs (J. R. Vockeroth). Montana. Gallatin Co.: Red Cliff Camp Ground, Gallatin Valley, meadow, Aug. 18, 1951, \& (H. and L. Levi). Colorado. Larimer Co.: Estes Park, 7800 ft., 1953, ô (H. and A. Jungster). Utah. Salt Lake Co.: East Canyon, June 12, 1943, \& (W. Ivie). California. Modoc Co.: 20 mi. N. of Canby, June 6, 1944, ô (W. M. Pearce). 

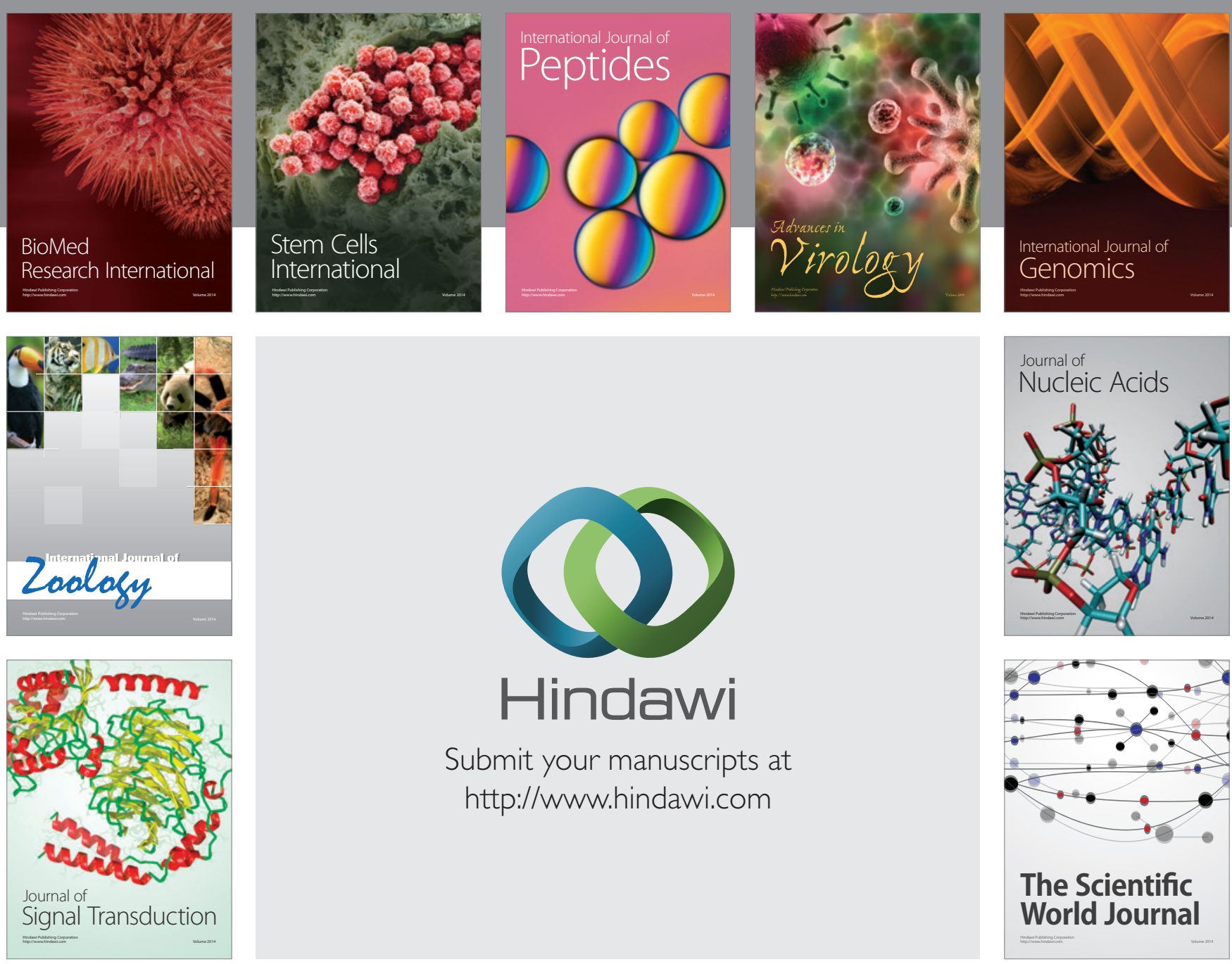

Submit your manuscripts at

http://www.hindawi.com
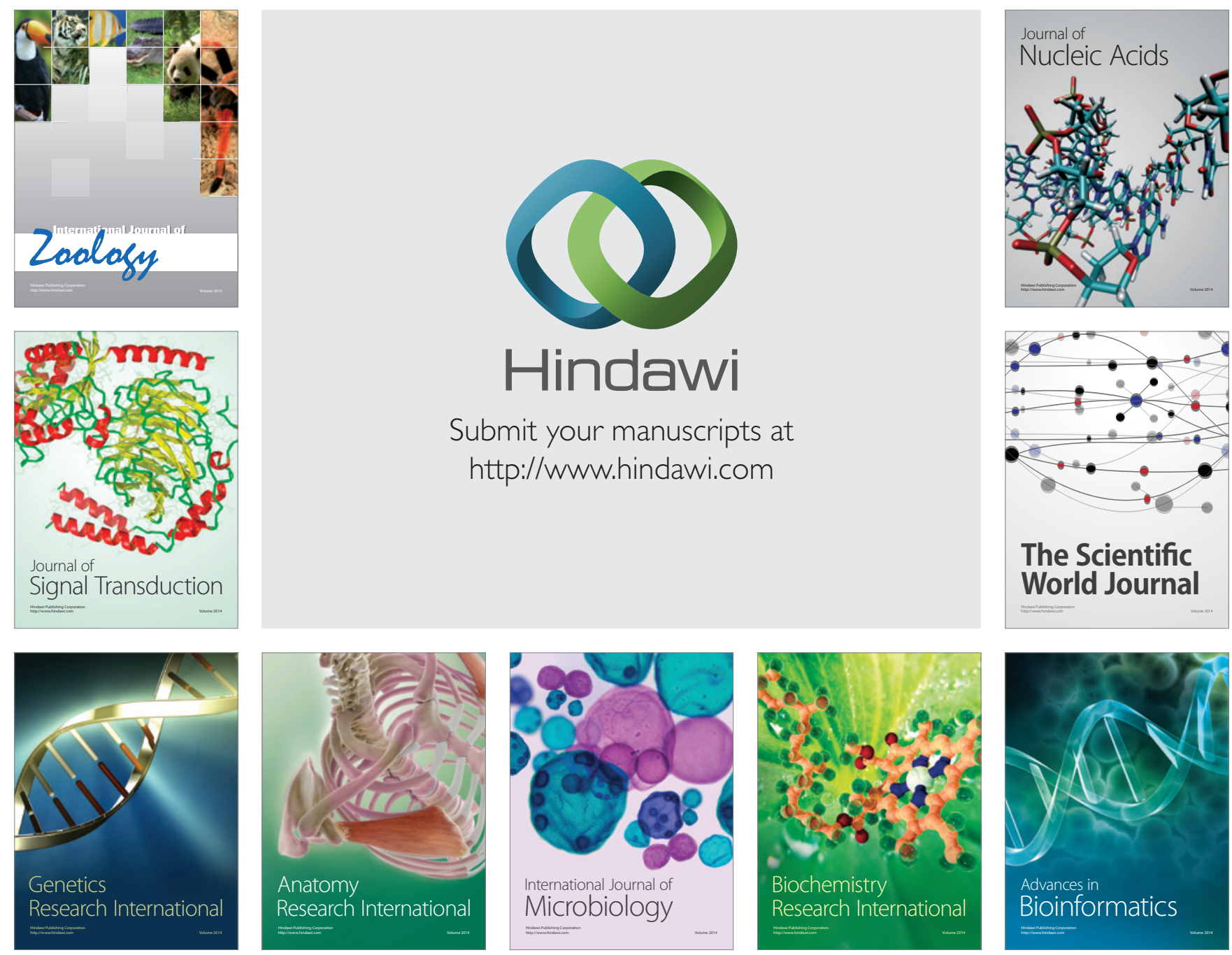

The Scientific World Journal
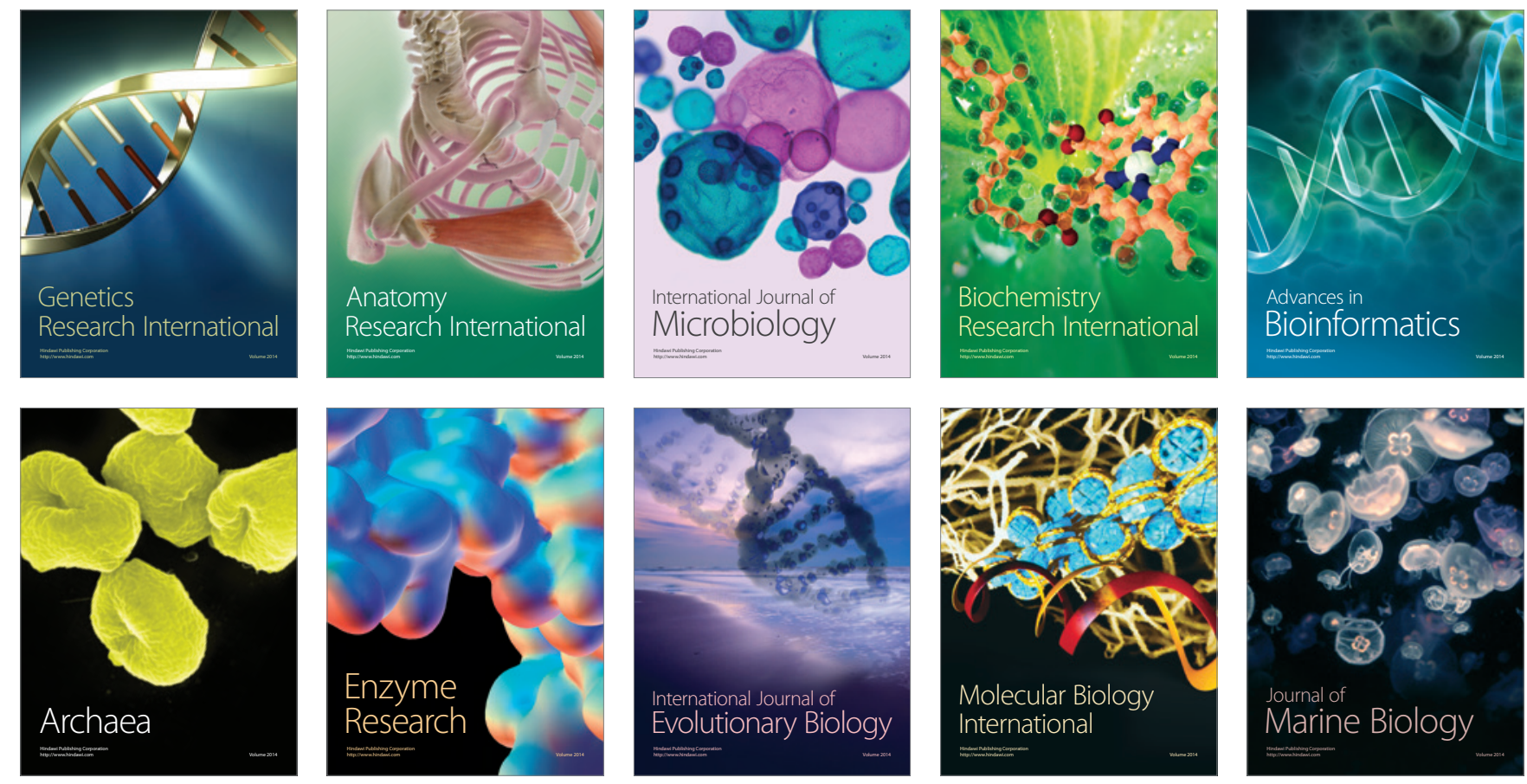